time to improve their interior energy absorption characteristics are likely to have to be devised.

(3) Since there is evidence that posterior dislocations of the hip can occur in the restrained car occupant (three cases were seen out of the 39 knee-impact hip injuries, in each of which the seat belt was being worn correctly and did not break, nor did the anchorage give way), it would seem prudent to accept that the energy absorption characteristics of the facia panel are important even when seat belts are used. It has been established (Lister and Neilson, 1966) that the wearing of diagonal or lap and diagonal seat belts can reduce the serious injury rate of car occupants by rather more than half. However, with car design as it is at present the degree of protection offered to the lower limbs is probably less than that offered, for example, to the head (Lister and Neilson, 1966 ; Grime, 1968, Grattan and Hobbs, 1968).

Our thanks are due to Mr. C. M. Squire, senior orthopaedic consultant surgeon, Battle Hospital, Reading, and to Mr. G. P. Arden, senior orthopaedic consultant surgeon, Windsor Group of Hospitals, for their assistance in the preparation of this paper; to Dr. H. J. Starks, of the Road Research Laboratory, for his advice ; and to Mr. J. C. Scott, director of accident services, United
Oxford Hospitals, Radcliffe Infirmary, Oxford, Mr. F. A. Simmonds, senior orthopaedic consultant surgeon, Royal Surrey Hospital, Guildford, Mr. Graham Apley, senior orthopaedic consultant surgeon, St. Peter's Hospital, Chertsey, and to Mr. J. B. Scott and Mr. P. J. Chesterman, consultant orthopaedic surgeons, Battle Hospital, Reading, for their courtesy in allowing patients to be examined on their wards. We also wish to thank Mr. W. Heath, of the Road Research Laboratory's photographic section, for the care with which the photographs of car interiors have been taken.

This article is contributed by permission of the Director of Road Research. Crown copyright. Reproduction by permission of the Controller of H.M. Stationery Office.

\section{REFERENCES}

Apley, A. G. (1963). A System of Orthopaedics and Fractures. London. Gögler, E. (1962). Road A:cidents, Series chirurgica No. 5. Basle. Grattan, E., and Hobbs, J. A. (1968). Mechanisms of Serious Lower Limb Injuries to Motor Vehicle Occupants, Report No. 201. Road Research Laboratory, Crowthorne.

Grime, G. (1968). Auto. Engr, 58, 292

Kulowski, J. (1960). Crash Injuries. Springfield, Illinois.

Lister, R. D., and Neilson, I. D. (1966). The Effectiveness of Safety Belts, Report No. 16. Road Research Laboratory, Crowthorne.

McLaughlin, H. L. (editor) (1959). Trauma. Philadelphia.

Watson-Jones, Sir Reginald (1955). Fractures and foint Injuries, 4th ed. Edinburgh and London.

- Senior Physician, Infectious Diseases Unit.

† Visiting Physician, Infectious Diseases Unit.

‡ Scientific Officer, Microbiology Department, Central Laboratory.

S Virologist, Microbiology Department, Central Laboratory.

Auckland Public Hospital, Auckland, New Zealand.

an exact causal relationship between virus and disease (Maisel et al., 1962).

The present series of 25 cases provides clinical and radiological evidence of pneumonia in which adenovirus type 21 may have had aetiological significance. A notable feature of this series is the high incidence of sequelae, $60 \%$ of survivors having residual lung damage.

\section{Material}

Twenty-five children ranging from 3 to 18 months of age were studied: 18 (72\%) were males and 7 (28\%) females. They were admitted to the Princess Mary Hospital for Children and the Infectious Diseases Unit, Auckland Hospital, during June to November 1965.

Table I gives the racial distribution. There is a striking preponderance of Polynesians-that is, both New Zealand born Maoris and immigrants from the Polynesian Islands lying to the north of New Zealand. In a city inhabited by $90 \%$

TABle I.-Racial Distribution

\begin{tabular}{ll|c|c|c}
\hline Race & $\begin{array}{c}\text { No. of } \\
\text { Cases }\end{array}$ & $\begin{array}{c}\% \\
\text { of } \\
\text { Series }\end{array}$ & $\begin{array}{c}\% \text { in Auckland } \\
\text { Population } \\
0-4 \text { Years }\end{array}$ \\
\hline Islanders & $\ldots$ & 10 & 40 & $\begin{array}{r}5.6 \\
\text { Maoris . }\end{array}$ \\
$\begin{array}{l}\text { Europeans } \\
\text { Others . }\end{array}$ & $\ldots$ & $\underline{2}$ & $\underline{8}$ & $\begin{array}{r}80.9 \\
0.9\end{array}$ \\
\hline
\end{tabular}


Europeans ( $80 \%$ in the $0-4$ age group) just over $90 \%$ of our cases came from families of Polynesian stock.

\section{Methods}

Pharyngeal secretions were obtained on the day of admission by swabbing the posterior pharyngeal wall with a cotton swab, which was then broken off into $2 \mathrm{ml}$. of veal infusion broth. Specimens were held at $5^{\circ} \mathrm{C}$. in transit to the virus laboratory, where after vigorous mechanical agitation and removal of the swab they were centrifuged for 10 minutes at 3,000 r.p.m. and $5^{\circ} \mathrm{C}$. Additional pharyngeal swabs were obtained and inoculated routinely on to bacteriological culture media.

Virus isolation procedures over the period in question were restricted to inoculation of HEp2 tube cultures. HEp2 cells were grown in Eagle's basal medium containing $8 \%$ heated calf serum, sodium bicarbonate at $88 \mathrm{mg} . / 100 \mathrm{ml}$., and penicillin (100 units $/ \mathrm{ml}$.) and streptomycin $(100 \mu \mathrm{g} . / \mathrm{ml}$.). Tubes were incubated at $36^{\circ} \mathrm{C}$. in sloping racks until confluent monolayers were obtained. They were then inoculated with $0.2-\mathrm{ml}$. volumes of clinical specimens and rolled at $36^{\circ} \mathrm{C}$. for 24 hours; the medium was then renewed and incubation continued for variable periods up to 14 days, at which time "negative" cultures were subjected to blind passage. Daily microscopical examination after an initial three to four days' incubation permitted recognition of characteristic adenovirus-type cytopathogenic effects in a number of cases. Passage material and virus isolates were stored at minus $30^{\circ} \mathrm{C}$.

Adenovirus isolates were identified in tissue culture neutralization tests based on the method of Grayston et al. (1956).

Rabbit antisera were prepared according to Rowe et al. (1955) against adenovirus isolates that were not neutralized by antisera of types 1-7, and against adenovirus type 21 (kindly provided by Dr. M. S. Pereira, of the Virus Reference Laboratory, P.H.L.S., Colindale Avenue, London N.W.9, England).

Sera were obtained from most patients within 48 hours of admission and at variable times in the course of illness thereafter.

Complement-fixation tests were made by the technique of Bradstreet and Taylor (1962) on W.H.O. plastic plates using 0.1-ml. unit volumes. In all cases fixation was carried out at $5^{\circ} \mathrm{C}$. overnight, and three $\mathrm{HC}^{\prime}{ }_{50}$ units of complement were used. A full range of serum, antigen, and complement controls was run with each batch of tests.

Adenovirus complement-fixing antigen was prepared in HEp2 cell cultures with type 7 adenovirus, and cultures were harvested when cytopathic effects were almost complete. Following a single freeze-thaw cycle the cells and medium were subjected to low-speed centrifugation, and the supernatant therefrom comprised the soluble adenovirus antigen.

Parainfluenza and respiratory syncytial complement-fixing antigens were prepared in primary human embryo kidney cultures maintained in medium 199 supplemented by $0.2 \%$ bovine albumin and harvested when cytopathic effects were advanced. Uncentrifuged frozen-thawed culture fluids, after being checked for specificity, constituted the antigens; they were titrated, ampouled, and stored at minus $96^{\circ} \mathrm{C}$. in a Revco freezer until used.

\section{Results}

Adenovirus isolations were made from pharyngeal secretions of 21 children and also from fluid obtained by lung puncture in two of these cases. All adenovirus isolates were serologically identified as type 21 by tissue culture neutralization tests.

No isolations of respiratory syncytial virus were made, though the HEp2 cell line used has previously and subsequently enabled isolation of respiratory syncytial virus under conditions identical to those employed here ; nor were rising complementfixing antibody titres against respiratory syncytial virus detected even relatively late in convalescence.

In Cases 1-6, as well as isolation of adenovirus type 21, rising high titre of complement-fixing antibody against adenovirus soluble antigen was also shown, concurrently with the acute clinical illness. Significant adenovirus complement-fixing antibody rise was also detected in cases 9-12 (Table II), in which no virus isolation was made. Several extremely high complementfixing antibody titres (up to $1: 16,384$ ) were the subject of repeated careful checking in batches of tests that included up to six negative sera as controls. Five cases (Nos. 1, 2, 3, 11, and 12) showed significantly increased titres of complement-fixing

TABLE II.-Virus Isolates, Serological Findings, and Bacteriology

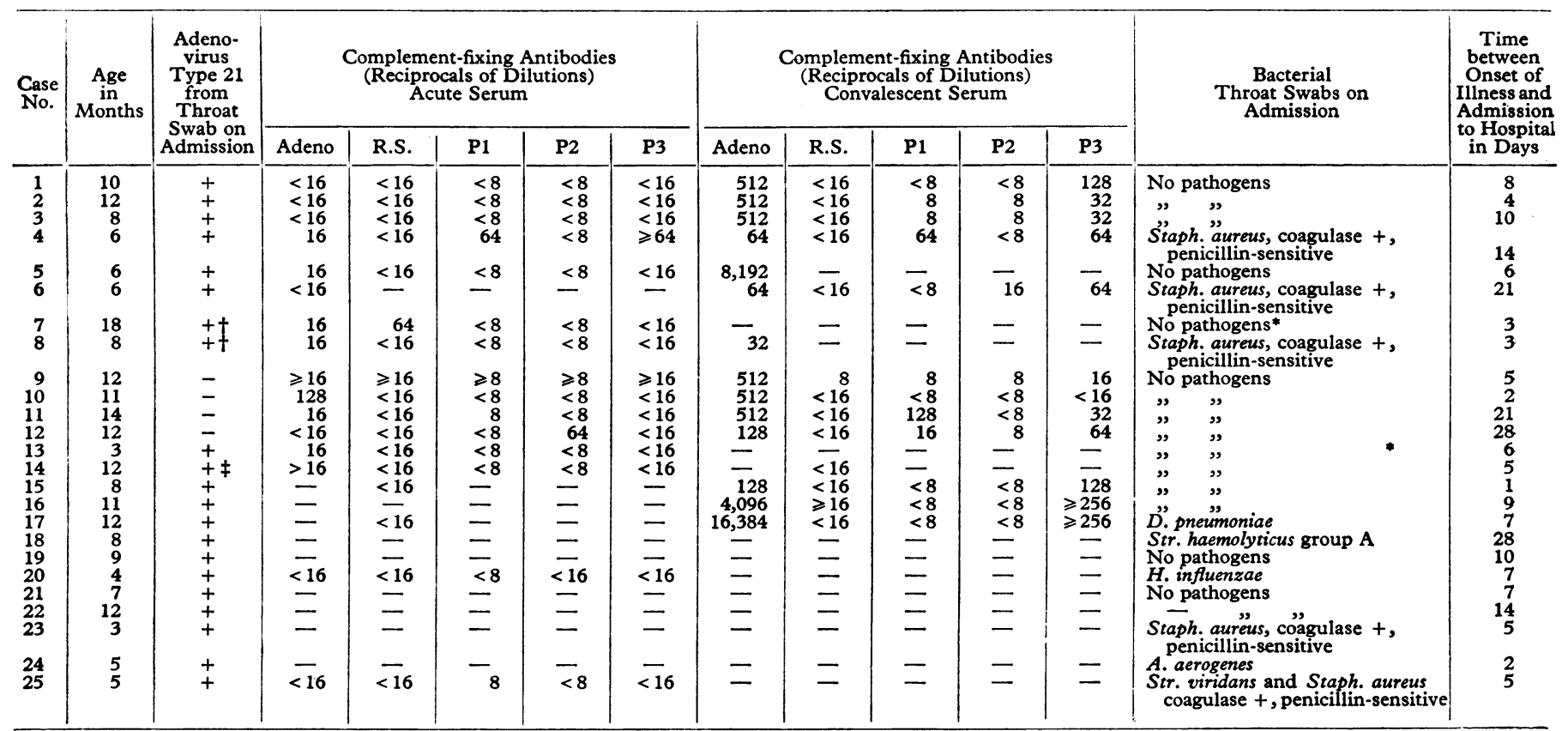


antibody against parainfluenza type 3 and a single case (No. 11) showed antibody rise against parainfluenza type 1 .

The scheme of starting dilutions for complement-fixing antibody titration had been used routinely by this laboratory for several years before 1965, and has been found satisfactory for detection of significant antibody rises, convalescent infant sera having been routinely used in box titrations to determine the antigen concentrations required for greatest sensitivity. Mycoplasma isolation and serology were not available at the time of this study.

Examination of throat swabs taken on admission showed no pathogens in 16. In the remaining nine, Staphylococcus aureus, coagulase-positive penicillin-sensitive, was isolated in five, and Haemophilus influenzae, Streptococcus haemolyticus (group A), Diplococcus pneumoniae, Aerobacter aerogenes, and Str. viridans were each found in one instance.

Table III summarizes the outcome: $60 \%$ of patients had evidence of residual lung damage, $20 \%$ had bronchiectasis, and two patients died.

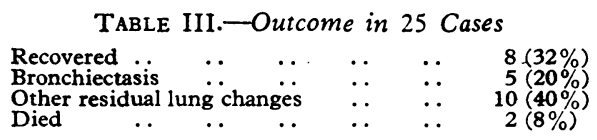

\section{Clinical Features}

Table IV summarizes the early signs and symptoms. Typical of most was a history before admission of several days of persistent cough and fever, neither having responded to antibiotics. Examination revealed moderate to severe dyspnoea, scattered moist sounds on auscultation, and wheezing. Obvious clinical signs of pneumonic consolidation were more often than not absent. Wheezing was particularly prominent, being both inspiratory and expiratory and unrelieved by antispasmodics. It was interpreted as evidence of obstructive lung disease, and occurred with or without an excess of secretions.

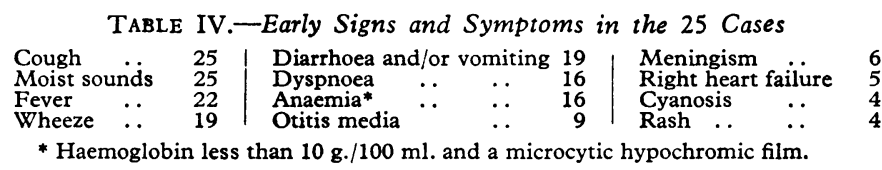

The infants were obviously ill, many having non-specific symptoms such as diarrhoea and/or vomiting, anorexia, dehydration, and irritability. Temperatures ranged from 38 to $40^{\circ}$ C., and usually there was some pyrexia for three to seven days after admission. Four were cyanosed at some time during the first week of observation. During the acute phase of those worst affected, right heart failure occurred (five cases), manifested by enlargement of the liver, distension of neck veins, cyanosis on coughing, oedema, atrial fibrillation (one case), an electrocardiographic pattern of right heart strain, and radiological enlargement of the right ventricle.

Malnutrition was a feature of the series. Sixteen had irondeficiency anaemia as evidenced by haemoglobin values of less than $10 \mathrm{~g} . / 100 \mathrm{ml}$., and microcytic hypochromic blood pictures. Thirteen were below the 25 th percentile in weight. In only nine did anaemia and low weight coexist. This is discussed below. One child had frank rickets. Rubella-like rashes were seen or reported to have occurred in four cases. These rashes were fleeting and mild, lasting only about 24 hours, and were unaccompanied by conjunctivitis. Upper respiratory signs, apart from otitis media in nine, were minimal.

Meningism without abnormality of the cerebrospinal fluid was seen in six cases. Fits occurred in three. These were thought to be febrile convulsions in two, aggravated by anoxia in one. In a third there was a temporary right hemiplegia, possibly associated with cerebral venous thrombosis in a severely dehydrated child. Heaf or Mantoux tests were negative in all 25 cases.

A characteristic of the more severe cases was a waxing and waning of the severity of illness over periods of up to several weeks. In the later stages of some, exacerbations of illness may have been attributable to secondary bacterial infection. However, repeated throat swabs and tracheal aspirates gave no evidence of consistent significant infection with any particular pathogens.

Staph. aureus, coagulase-positive, was isolated briefly from a few cases in numbers reported on as forming "a few colonies." More frequent isolates were made of Str. viridans and non-haemolytic streptococci. An occasional pneumococcus, pseudomonas, $H$. influenzae, and Staph. aureus, coagulase-negative, were found. Most commonly the flora consisted of Neisseria catarrhalis, paracolon bacilli, and Escherichia and Klebsiella species.

No fewer than 12 patients were readmitted after apparent partial or complete recovery from their initial illnesses.

\section{Treatment}

Benzylpenicillin, cloxacillin, and ampicillin were given in most cases. Tetracyclines were used separately in several. No benefit was observed from any of these antibiotics. The same can be said in general for antispasmodics such as isoprenaline and aminophylline. Fluid replacement orally or intravenously, humidification of air, suctioning via endotracheal tubes, oxygen, and physiotherapy were the principal means of treatment. Humidification was achieved mainly by plastic cone and East humidifier. Several cases required treatment in the near-by acute respiratory unit, where they received assisted ventilation with intermittent positive pressure after curarization together with cooling to $32^{\circ} \mathrm{C}$. if cerebral oedema was suspected. Monitoring of blood gases, fluids, and electrolytes at frequent intervals was routine for the most severe cases.

The same principles were followed in the management of exacerbations. Where prolonged antibiotic therapy was used the endeavour was made to restrict it to the narrow-spectrum drugs benzylpenicillin and cloxacillin in an attempt to avoid superinfection with Gram-negative organisms and yeasts.

The impression was gained that useful prophylaxis was achieved by the above physical and chemotherapeutic measures, but that the underlying pathological condition was not bacterial in origin and therefore not affected.

\section{Radiological and Pathological Findings}

The radiological findings are illustrated in more detail by the case presented below. In summary, they consisted of bronchial, peribronchial, and interstitial inflammatory changes going on to areas of patchy bronchopneumonia with collapseconsolidation of larger or smaller portions of lung. In keeping with the clinical picture, radiological changes were seen to wax and wane over many days or weeks. Pleural reactions with fluid were minor features in the first month in two cases. Mediastinal lymphadenopathy appeared to be marked in two cases several weeks after their admission. Residual fibrosis with crowding of bronchi was diagnosed in 10 (40\%) of the cases. Three had permanent massive collapse of a lung. Air bronchograms were common. Bronchiectasis as shown by contrast medium was present in five and seen at necropsy in another.

The pathological findings will be reported separately (Becroft, 1968). From the cases coming to necropsy no early pathological specimens were available. The most striking 
feature of the material obtained in the later stage was an obliterative bronchiolitis. Bronchiectasis, where this developed, seemed to be secondary to the primary bronchiolar lesions.

The following case is typical of many in which the patient survived. Those who died will be reported on separately (Becroft, 1968).

\section{Case 2}

This year-old Island boy came to hospital with a history of "measles" four days before admission but no sign of a fading rash. His temperature was $40^{\circ} \mathrm{C}$. $\mathrm{He}$ was dehydrated and dyspnoeic, with a respiratory rate of 65 per minute. Widespread moist sounds were heard in his chest. Haemoglobin, white cell. and differential counts, and electrophoresis of serum proteins were normal. A throat swab showed no bacterial pathogens.

A chest $x$-ray film on admission (Fig. 1) showed abnormal density in the right mid and lower zones, with increased lung markings

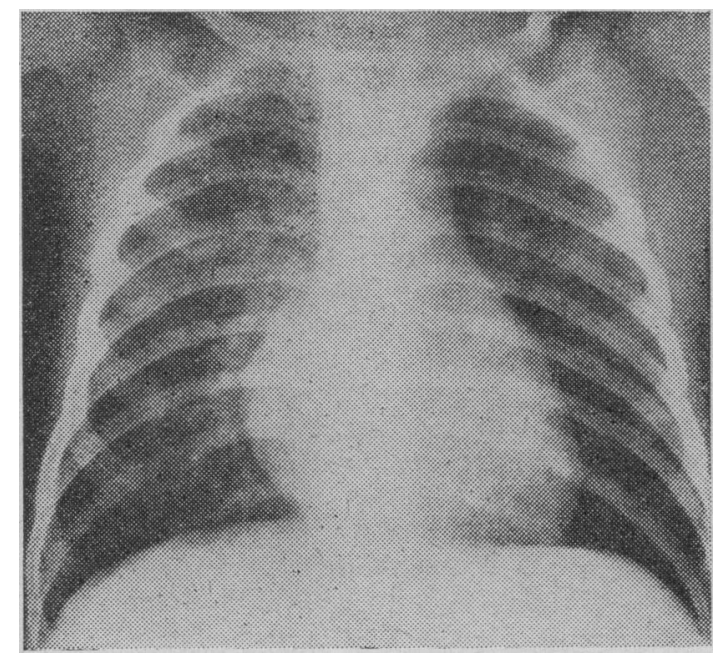

FIG. 1.-Case 2. Bronchopneumonic consolidation and interstitial inflammatory changes on admission.

towards the right base and left upper zone. The right upper zone had the appearance of a clearing bronchopneumonic consolidation. Elsewhere there were interstitial inflammatory changes.

There was no obvious response to cloxacillin or ampicillin, though the child gradually improved over a period of 20 days. At this time he was allowed home. His chest $x$-ray picture was almost clear.

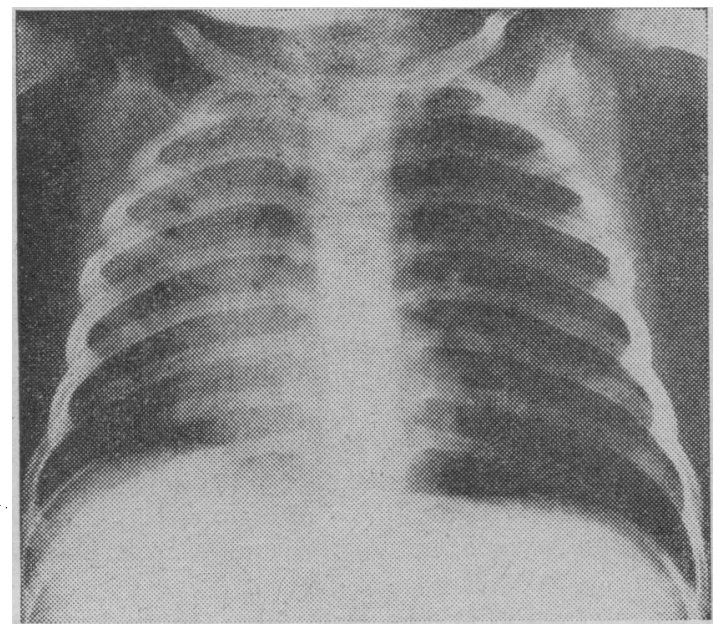

FIG. 2.-Case 2. Deterioration with partial collapseconsolidation of right lung on readmission 32 days after first admission.
Twelve days later he was readmitted with signs of collapseconsolidation of the right lung (Fig. 2), an enlarged liver, and dyspnoea. He was afebrile and remained so. There was no leucocytosis, and a throat swab grew only Str. viridans and $N$. catarrhalis. After a further 12 days he was clinically but not radiologically much improved. He was no longer dyspnoeic, and his liver had returned to a normal size. Little change then occurred over the next month, after which he was discharged to be followed up as an outpatient.

Eleven weeks from the onset of his illness he was readmitted for a bronchogram (Fig. 3). This showed moderate bronchiectatic changes in all segments of the right lung, and minor bronchial dilatation of the apical segments of the left lower lobe.

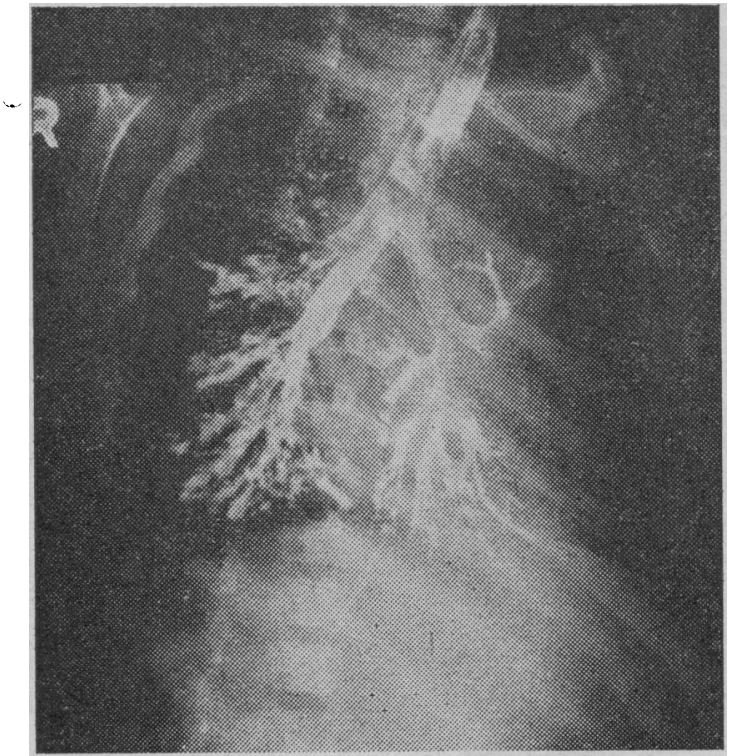

FIG. 3-Case 2. Bronchogram 11 weeks after onset of illness, showing no major bronchial occlusions but bronchiectatic changes throughout right lung.

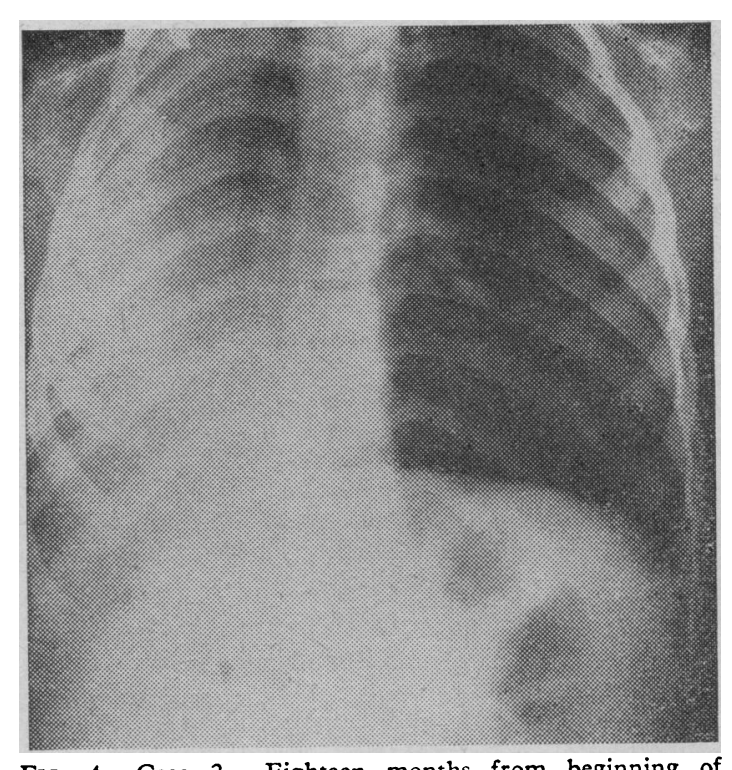

Fig. 4.-Case 2. Eighteen months from beginning of illness. The right lung is completely collapsed.

Fifteen months later a plain film (Fig. 4) showed further collapse of the right lung with displacement of the heart and mediastinum and herniation of the left lung to the right.

This case shows features common to most-namely, patchy areas of bronchopneumonia appearing, partially clearing, and reappearing throughout both lungs. In the early stages improvement was so marked that the child was allowed home, only to return with a 
relapse ending in collapse of the right lung and bilateral bronchiectasis. His physical development has remained retarded, and he has a chronic cough and wheeze and a tendency to repeated chest infections.

\section{Follow-up Studies}

The outcome in this group of children has already been noted (Table III). Follow-up was not always possible, as some parents failed to report back with their children. Similarly, premature discharge from hospital was the case with several infants, their Polynesian parents insisting on taking their children home. Except for one child, all survivors were seen one month or more after discharge. Ten were seen at intervals for more than six months. The longest follow-up period to date is three years and six months.

Chronic cough, repeated chest infections, and wheezing were the main sequelae in 14 of the 23 survivors. A further child suffered from "asthma." Eight made apparently complete recoveries. Those most severely affected were physically retarded and dyspnoeic on exertion. Dyspnoea appeared to be pulmonary in origin. Recovery from right heart failure was complete where death did not occur.

Five developed bronchiectasis-four widespread and inoperable (Fig. 5) and one localized (operation refused). One without bronchiectasis had a lobectomy. This was performed at another hospital, and the resected portion of the lung showed gross destruction and fibrosis. Unfortunately it was not retained for histological or virological study.

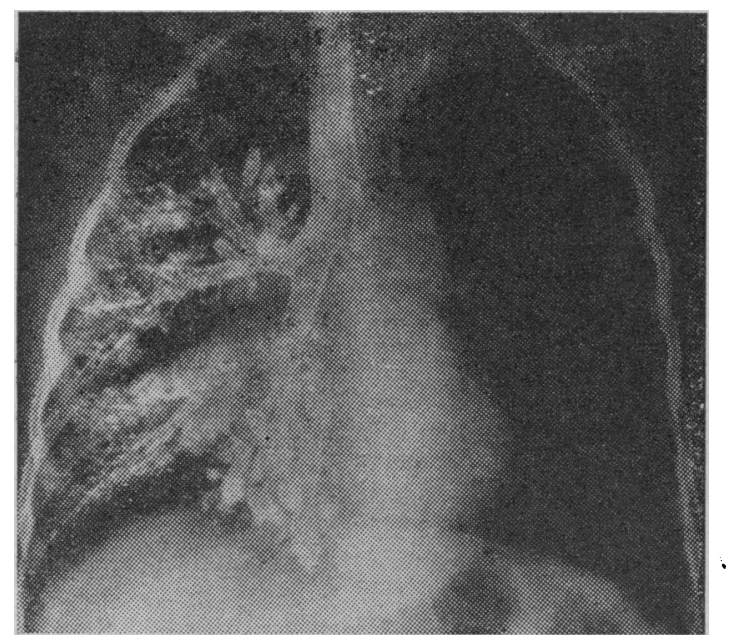

FIG. 5.-Case 9. Bronchogram showing bronchiectasis in right lower lobe and posterior segment of right upper lobe.

\section{Epidemiology}

Table $\mathrm{V}$ shows the distribution of cases over the winter months of 1965 . Beginning in June, the cases rose to a peak in August and ended with one case admitted on 1 November.

Table V.-Case Rate by Months

\begin{tabular}{l|c|c|c|c|c|c}
\hline $\begin{array}{l}\text { Month (1965) } \\
\text { No. of cases }\end{array}$ & $\begin{array}{c}\text { June } \\
\text { July }\end{array}$ & $\begin{array}{c}\text { August } \\
11\end{array}$ & $\begin{array}{c}\text { September } \\
6\end{array}$ & October & $\begin{array}{c}\text { November } \\
1\end{array}$ \\
\hline
\end{tabular}

It is of interest that during this period no adenoviruses other than type 21 were isolated in Auckland. Types 1, 2, 3, 7, and 12 were grown at various times during the months of January to May and again in December 1965.
Owing to the retrospective nature of this study a control group free from respiratory infection was not obtained. During the period under study 39 Polynesian children of comparable age with respiratory illnesses not resembling those in our series had throat swabs examined for adenoviruses and some serology performed. No adenoviruses were grown. Twelve of these children had paired sera, none of which showed a rise in titre of complement-fixing antibody to adenovirus. Eleven had positive complement-fixation titres in the range $1: 16$ to $1: 32$. These 39 children did not include 18 who in fact had illnesses resembling those in our series but who had inadequate virological study to qualify them for admission. Of these 18 six had complement-fixation titres to adenovirus ranging from $1: 64$ to $1: 2,048$.

Also in the same period sera were examined from 213 other children aged up to 10 years-Europeans and Polynesiansadmitted to the same wards as those in our series with a variety of infectious and non-infectious conditions: 161 showed no complement-fixing antibodies to adenovirus and 52 had titres ranging from $1: 16$ to $1: 4,096$. It is not known what adenoviruses these children had encountered nor when they had acquired antibody.

A few children in the series were nursed initially in cubicles, but the majority were in small rooms containing two to six children. Later some were transferred to larger open wards. On virological as well as clinical grounds none of the series seems to have acquired adenovirus infection in hospital. The onset of illness in 18 suspects not included in the series indicated strongly that they too had acquired their illnesses before coming to hospital.

There were no recognized concurrent viral infections of epidemic proportions in the child or adult population that may have contributed to or have exaggerated the clinical response of the cases under study to adenovirus type 21 . A relatively small number of cases of croup were being admitted to the infectious diseases unit. Contact between these cases and those in the adenovirus group was certainly possible. Though none of the latter showed signs of croup no fewer than five had rising titres to parainfluenza 3 and one to parainfluenza 1 (Table II).

Influenza myxoviruses were not isolated or suspected to be prevalent during this respiratory disease season.

Sporadic cases of measles were present in Auckland in the winter of 1965 . The total measles admissions to the infectious diseases unit for the year were only 12. None of the four cases with rashes in the series was thought to have measles clinically. One aged 12 months was said to have had morbilli a few months before admission. Another developed typical measles some months after admission to hospital. Fourteen were aged 3 to 9 months, and may thus have had adequate protection from maternal antibodies.

Neither Table II (throat swabs on admission) nor the evidence from subsequent throat or tracheal swabs (see Clinical Features) points to the implication of any particular bacterial pathogen, including the tubercle bacillus, in either the acute or chronic stages.

Case 16 was the only one of the series in which, fortuitously, at a later date convalescent serum was examined for complement-fixing antibodies to Mycoplasma pneumoniae. The titre was less than $1: 8$. Four other children with similar clinical illnesses but not included in the series because of incomplete data also had negative convalescent titres.

An important feature of this study is its possible relevance to the relationship between a severe viral infection and malnourishment among less socially privileged peoples. The evidence so far as our cases are concerned is as follows: $16(64 \%)$ had iron-deficiency anaemia, $13(52 \%)$ had a weight below the 25 th percentile, and $9(36 \%)$ whose weight was between the 25 th and 97 th percentiles were markedly anaemic. 
Experience with Polynesian children leads us to believe that many are fed on a very high carbohydrate diet, deficient in protein, vitamins, and minerals, especially iron.

The homes of 12 children were classified by European standards as very poor, five were satisfactory, and in eight cases the necessary information is lacking.

Some data are available from a survey at present being undertaken on children in hospital in Auckland (M. Hardy, personal communication, 1968). Approximately 300 children with malnourishment of dietary origin uncomplicated by other medical or surgical causes have been assessed to date. All had weights below the 25 th percentile. Over half were Maoris, one-sixth were Islanders, and one-quarter were Europeans. In 54 of the 300 the haemoglobin values were below $8 \mathrm{~g} . / 100 \mathrm{ml}$. Among these 54 the above proportions of Maoris, Islanders, and Europeans were again almost identical. In conjunction with the population statistics noted in Table I, these figures indicate very definite malnutrition among the Polynesians in Auckland.

Ignorance of European conditions and foods appeared to be the problem among Islanders, whose homes, for the most part, were clean and well kept. Maoris, on the other hand, tended to be easygoing, feckless, and careless of their hygienic standards. It should be noted that these comments apply to the city population under study, and do not necessarily reflect the state of affairs among Islanders or Maoris as a whole. Overcrowding occurs commonly in the homes of both.

Europeans constituted only $5 \%$ of those from bad homes among the malnourished children surveyed. Malnutrition by any criteria is very much the exception among Europeans in New Zealand.

The pattern of illnesses in general and respiratory diseases in particular differs chiefly quantitatively between Maoris and Islanders on the one hand and Europeans on the other. An exception is mucoviscidosis, no example of which has come to our notice among Polynesians. Respiratory infections of all kinds affect Polynesians much more frequently than Europeans. Few Maori children escape without some loss of hearing due to otitis media.

Bronchiectasis differs both quantitatively and qualitatively among Europeans and Polynesians. Hinds (1958) surveyed 163 bronchiectatics attending the Chest Unit, Greenlane Hospital, Auckland-94 were Europeans, 65 Maoris, and 4 Islanders. At that time the relative population of Europeans to Maoris was nine to one, Islanders being very few in number. Bronchiectasis requiring treatment was relatively five times more frequent among Maoris than among Europeans. Maoris had a predilection for extensive cystic and saccular forms of bronchiectasis whereas Europeans tended to have less extensive cylindrical disease. The four Islanders were noted to have particularly severe bronchiectasis.

\section{Discussion}

The cases as listed in Table II fall into three categories as regards the likelihood that adenovirus type 21 was causal in the production of what is thought to have been a uniform clinical picture. (1) Cases 1 to 6 , where the virus was isolated from throat swabs and there were significant rises in complementfixing antibody titre. Neutralizing antibody to adenovirus type 21 was present in the convalescent serum of Case 5. (2) Cases 7 and 8, where adenovirus was isolated on lung puncture. (3) Cases 9 to 12, in which significant rising complementfixation titres to adenovirus (type unknown) were demonstrated, and Cases 13 to 25 , in which adenovirus type 21 was isolated from throat swabs but serological evidence was missing or incomplete. Neutralizing antibody to adenovirus type 21 was present in the convalescent serum of Cases 16 and 17.
A fairly strong claim may be made for the first category. The third is included particularly for its epidemiological value, there being no clinical distinction to be made between its members and those of category 1. Category 2 lies intermediate.

Of three in whom a fourfold or greater rise in complementfixing antibody titre was not demonstrated yet in whom a single serum showed a titre of more than $1: 128$, the high titre might be supposed to have originated from maternal antibody. However, all were over 6 months of age and might therefore be expected to have lost maternal antibody. Five in whom single sera only were available had titres of $1: 32$ or less; three were under and two over 6 months of age. Again, 161 of 213 other children tested by the same method during the same period had no demonstrable complement-fixing antibodies to adenovirus.

Five cases (Nos. 1, 2, 3, 11, and 12) had significant rises in titres to parainfluenza 3 virus. Case 11 also had a similar rise to parainfluenza 1. Three of these cases fall into category 1 above. It may be reasoned that on virological grounds the evidence for adenovirus being the significant pathogen in these three cases is stronger than that for either myxovirus. Cases 11 and 12 must remain in doubt. None of these cases had clinical croup, nor have we encountered parainfluenza viruses in association with a clinical syndrome such as we have described in this paper.

In recounting the epidemiological features the possible roles for respiratory syncytial virus, influenza, measles, mycoplasma, and bacteria have been discussed. It must be admitted that we did not obtain laboratory evidence of infection or otherwise with these viruses during the prolonged course of our cases, nor of whether adenovirus type $21 \mathrm{did}$ or did not persist in the respiratory tract.

Future studies must confirm or deny our impression that adenovirus type 21 was in fact the aetiological agent in the disease observed. The facts presented do not, we believe, favour a bacterial cause for either the initiation or the perpetuation of the illnesses seen.

The clinical and radiological picture of bronchiolitis and relapsing bronchopneumonia was a uniform one in the 25 cases. Before laboratory evidence was obtained an adenoviral cause was suggested because of previous experience by one of us (W. R. L., unpublished) with two cases of pneumonia associated with adenovirus type 7 .

A complete characterization of pneumonia associated with adenovirus type 21 will not be possible until detailed pathological studies have been made. The findings from postmortem material from this series will go some way to help in this direction (Becroft, 1968); but more extensive material, especially from cases early in the disease, is urgently required. Massive necrosis of bronchiolar epithelium was not apparently a feature of this series as it has been in cases involving other adenovirus serological types (Becroft, 1967). Rather it would appear that less severe initial damage was followed by cellular proliferation with airways obstruction.

The present series seems to indicate a particular susceptibility of young children to adenovirus type 21 infection. The predominance of males is difficult to explain.

Two further possible factors require consideration. In favour of a genetic factor is the striking racial incidence. All except two cases were Polynesians, a minority group in a predominantly European city. Hinds (1958), in his study on bronchiectasis in the Maori, gives three possible explanations for the high incidence of that disease in the Polynesian race. First is the fact that more severe, perhaps neglected, childhood respiratory infections occur among Polynesians than among Europeans. Hinds does not mention specifically in this connexion either pertussis or measles. He also dismisses tuberculosis as a significant contributing disease. As a second possibility Hinds suggests " an inability of the native to cope with pulmonary infections as efficiently as his European counter- 
part." Thirdly, he asks the question, "Or is there some congenital factor operating, giving rise to what may be termed an 'organ inferiority' in respect of the Polynesian lung ?"

One finding, the relevance of which to the present study cannot be denied, is the degree of malnutrition among Polynesian babies compared with Europeans. Here is something tangible to which we believe great attention should be paid in similar future studies. Neither a genetic nor a nutritional factor for severe respiratory illness excludes the other. Further work will be required to elucidate the part played by either or both.

What of the adenovirus? Macfarlane and Sommerville (1957) wrote of a " non-tuberculous juvenile bronchiectasis; a virus disease ?" van der Veen (1963) stated: "Further studies are needed to elucidate the role of adenoviruses in the development of persistent bronchial lesions." Finally, Rytel et al. (1964) reported a very suggestive correlation between adenovirus infection and the subsequent development of bronchiectasis in naval recruits.

The present series suggests that adenovirus type 21 can produce lethal pneumonia or result in lung fibrosis or bronchiectasis in survivors. The question remains, could adenoviruses be of major importance in the as yet unknown aetiology of many cases of bronchiectasis?

We wish to thank Dr. D. M. O. Becroft, pathologist, Princess Mary Hospital for Children, and Dr. G. W. Dodd, radiologist,
Auckland Hospital, for considerable help in preparing this paper. Our thanks are also due to Drs. A. M. Bush, R. H. Caughey, and T. G. Fox for permission to quote data from cases under their care.

\section{REFERENCES}

Becroft, D. M. O. (1967). F. clin. Path., 20, 561.

Becroft, D. M. O. (1968). To be published.

Benyesh-Meln:ck, M., and Rosenberg, H. S. (1964). f. Pediat., 64, 83. Bradstrest. C. M. P., and Taylor, C. E. D. (1962). Mth. Bull. Minist. Hlth Lab. Serv., 21, 96.

Chany, C., Lépine, P., Lelong, M., Le-Tan-Vinh, Satgé, P., and Virat, J. (1958). Amer. 尹. Hyg., 67, 367.

Clarke, S. K. R., Corner, B. D., Gambier, D. M., Macrae, J., and Peacock, D. B. (1964). Brit. med. F., 1, 1536.

Grayston, J. T., Johnston, P. B., Smith, M. E., and Loosli, C. G. (1956). 7. infect. Dis., 99, 188.

Hinds, J. R. (1958). N.Z. med. 7., 57, 328.

Hsiung Chih-ch'üan (1963). China med. F., 82, 390.

Kawai, K. (1959). fap. F. exp. Med., 29, 359.

Macfarlane, P. S., and Sommerville, R. G. (1957). Lancet, 1, 770.

Maisel, J. C., Pierce, W. E., Crawford, Y. E., and Rosenbaum, M. J. (1962). Amer. F. Hyg., 75, 56.

Rowe, W. P., Huebner, R. J., Hartley, J. W., Ward, T. G., and Parrott, R. H. (1955). Amer. f. Hyg., 61, 197 .

Rytel, M. W., et al. (1964). Dis. Chest, 46, 23.

van der Veen, J., and Dijkman, J. H. (1962). Amer. F. Hyg., 76, 149. van der Veen, J. (1963). Amer. Rev. resp. Dis., 88, Supp. No. 167.

Wright, H. T., Beckwith, J. B., and Gwinn, J. L. (1964). f. Pediat., 64, 528.

\title{
Significance of Electrocardiographic Changes in Hypertension
}

\author{
JOHN HAMER,* M.D., PH.D., M.R.C.P. ; ELLIOT SHINEBOURNE, $\dagger$ M.B., M.R.C.P. \\ JAMES FLEMING, $\ddagger$ M.D., M.R.C.P.
}

Brit. med. F., 1969, 1, 79-82

\begin{abstract}
Summary : Studies in 17 hypertensive patients showed $\checkmark$ that the electrocardiographic features of $T$-wave inversion and S-T segment depression distinguish those patients with higher systolic blood pressures. They do not indicate impaired cardiac function.
\end{abstract}

\section{Introduction}

The electrocardiographic pattern of depression of the S-T segments and inversion of the $T$ waves in left-sided leads in a patient with systemic hypertension is generally accepted as evidence of severe left ventricular hypertrophy. The term "left ventricular strain" that is sometimes given to this electrocardiographic finding implies that left ventricular function may be impaired under these circumstances.

Our previous work (Hamer et al., 1967) has indicated that the cardiac output on exercise is lower than normal in patients with hypertension. In this study we have attempted to correlate the electrocardiographic changes with the degree of disturbance in left ventricular function as assessed from the response of the cardiac output to exercise.

* Consultant Cardiologist.
† Research Assistant.
† Senior Registrar.
Cardiac Department, St. Bartholomew's Hospital, London E.C.1.

\section{Patients and Methods}

Seventeen hypertensive patients aged from 22 to 64 were investigated. All had a diastolic pressure of $100 \mathrm{~mm} . \mathrm{Hg}$ or over as outpatients. The clinical findings are summarized in Table I. On the basis of the electrocardiogram they were divided into two groups (Table II). Nine (group I) had a

TABLE I.-Clinical Features

\begin{tabular}{l|l|l|l|l|l}
\hline Case & Sex & Age & $\begin{array}{c}\text { Casual } \\
\text { B.P. }\end{array}$ & $\begin{array}{c}\text { Fundal } \\
\text { Changes } \\
\text { (Graded } \\
\mathbf{0} \text { to 4) }\end{array}$ & \multicolumn{2}{|c}{\begin{tabular}{c} 
Chest \\
\cline { 3 - 5 }
\end{tabular}} & & CTR $\%$ & Congestion \\
\hline
\end{tabular}

\begin{tabular}{l|l|l|}
1 & $M$ & 40 \\
2 & $M$ & 46 \\
3 & $M$ & 62 \\
4 & $M$ & 45 \\
5 & $M$ & 59 \\
6 & $M$ & 36 \\
7 & $M$ & 39 \\
8 & $M$ & 24 \\
9 & $M$ & 50
\end{tabular}

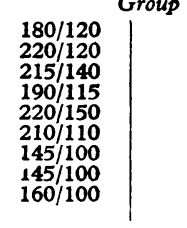

\begin{tabular}{l|l|}
3 \\
1 \\
2 \\
1 \\
0 \\
1 \\
1 \\
0 \\
0
\end{tabular}

\begin{tabular}{l|l}
42 & 0 \\
47 & 0 \\
48 & 0 \\
43 & 0 \\
56 & 0 \\
43 & + \\
48 & 0 \\
48 & 0 \\
42 & \\
& 0
\end{tabular}

\begin{tabular}{l|}
10 \\
11 \\
12 \\
13 \\
14 \\
15 \\
16 \\
17
\end{tabular}

\begin{tabular}{c|c}
$\mathbf{M}$ & 54 \\
$\mathbf{M}$ & 48 \\
$\mathbf{M}$ & 52 \\
$\mathbf{F}$ & 64 \\
$\mathbf{F}$ & 49 \\
$\mathbf{M}$ & 55 \\
$\mathbf{F}$ & 22 \\
$\mathbf{F}$ & 34
\end{tabular}

